\begin{tabular}{|c|c|}
\hline Title & $\begin{array}{l}\text { Synthesis and efficient circularly polarized light emission of an optically active hy perbranched poly(fluorenevinylene) } \\
\text { derivative }\end{array}$ \\
\hline Author(s) & $\begin{array}{l}\text { Yu, Juin-Meng; Sakamoto, Takeshi; W atanabe, Kento; Furumi, Seiichi; Tamaoki, Nobuyuki; Chen, Y un; Nakano, } \\
\text { T amaki }\end{array}$ \\
\hline Citation & $\begin{array}{l}\text { Chemical Communications, } 47(13), 3799-3801 \\
\text { https://doi.org/10.1039/0cc05564f }\end{array}$ \\
\hline Issue Date & 2011-04-07 \\
\hline Doc URL & http:/hdl.handle.net/2115/47985 \\
\hline Rights & Chem. Commun., 2011, 47, 3799-3801- Reproduced by permission of The Royal Society of Chemistry (RSC) \\
\hline Type & article (author version) \\
\hline File Information & CC47-13_3799-3801.pdf \\
\hline
\end{tabular}

Instructions for use 


\title{
Synthesis and efficient circularly polarized light emission of an optically active hyperbranched poly(fluorenevinylene) derivative
}

\author{
Juin-Meng Yu, ${ }^{a, b}$ Takeshi Sakamoto, ${ }^{a}$ Kento Watanabe, ${ }^{a}$ Seiichi Furumi, ${ }^{c}$ Nobuyuki Tamaoki, ${ }^{d}$ Yun \\ Chen $^{b}$ and Tamaki Nakano* ${ }^{a}$
}

\author{
5 Received 14th December 2010, Accepted 17th January 2011 \\ DOI: 10.1039/c0cc05564f
}

\begin{abstract}
An optically active, hyperbranched poly(fluorenevinylene) derivative was synthesized by polymerization of (-)-2,4,7tris(bromomethyl)-9-neomenthyl-9-pentylfluorene. A spin10 coated film sample of the polymer exihited efficient circularly polarized light (CPL) emission in the visible range of $400-700 \mathrm{~nm}$ on photo excitation even without annealing processes leading to chain ordering.
\end{abstract}

Luminescent organic polymers are important as materials for 15 organic light-emitting diodes (OLEDs) due to their tunable emission properties through molecular design and their inherent flexible nature and readiness in fabrication. ${ }^{1}$ The most widely-studied luminescent polymers such as poly( $p$ phenylenevinylene), ${ }^{2}$ polyfluorene, ${ }^{1 \mathrm{~b}}$ and their derivatives ${ }^{3}$ 20 have linear conjugated structures. However, for these polymers, interchain interactions are known to result in a lowenergy emission and low emission efficiency due to excimer formation. ${ }^{4}$ In order to circumvent this drawback, threedimensional, dendritic and hyperbranched conjugated 25 polymers have been devised. ${ }^{5-7}$

Herein, we present the synthesis and properties of a novel, chiral hyperbranched poly(fluorenevinylene) derivative. Chirality was readily introduced to the polymer chain by polymerizing optically active (-)-2,4,7-tris(bromomethyl)-930 neomenthyl-9-pentylfluorene (monomer) (a mixture of two diastereomers, $[\alpha]_{\mathrm{D}}{ }^{25}-58^{\circ}\left(\mathrm{CHCl}_{3}, 1 \mathrm{~g} / \mathrm{dL}, 0.1-\mathrm{dm}\right.$ cell $)$ ) having a chiral group attached to the 9-position of fluorene moiety (Scheme 1). The chiral polymer was designed after the achiral, parent polymer having two hexyl groups at the 935 position of fluorene ring. ${ }^{\text {a }}$ The obtained polymer efficiently emitted circularly polarized light (CPL) without annealing processes. This observation is in sharp contrast to the fact

$4^{a}{ }^{a}$ Division of Biotechnology and Macromolecular Chemistry, Faculty of Engineering, Hokkaido University, Sapporo 060-8628, Japan. E-mail: nakanot@eng.hokudai.ac.jp; Fax: +81 11706 6869; Tel: +81 11706 6606

${ }^{b}$ Department of Chemical Engineering, National Cheng Kung University, 45 Tainan, Taiwan

${ }^{c}$ National Institute for Materials Science (NIMS) 1-2-1 Sengen, Tsukuba, Ibaraki 305-004, Japan

${ }^{d}$ Research Institute for Electronic Science, Hokkaido University, Sapporo 010-0020 Japan

$50 \dagger$ Electronic Supplementary Information (ESI) available: Experimental details including monomer and polymer syntheses, ${ }^{1} \mathrm{H}$ NMR spectra and TGA and DSC charts, and CPL transmission spectra. See DOI: $10.1039 / \mathrm{b} 000000 \mathrm{x} /$

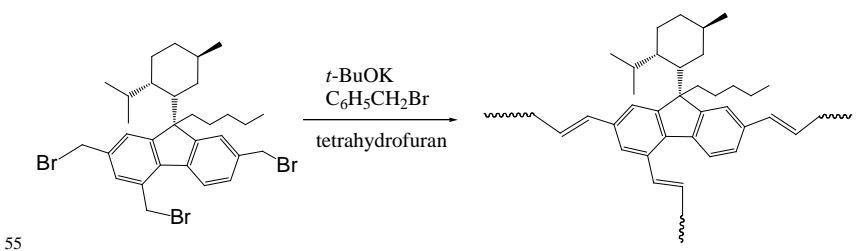

Scheme 1. Synthesis of an optically active, hyperbranched polymer.

60 that molecular ordering such as aggregate or liquid crystalline formation achieved by annealing has been the major trend of research toward efficient CPL emission. ${ }^{8,9}$

The polymerization was carried out in tetrahydrofuran (THF) under conditions similar to those applied for the achiral, ${ }_{65}$ parent polymer. $^{7 \mathrm{a}}$ The reaction of the monomer with $t$-BuOK and benzylbromide was conducted to afford a polymer soluble in THF and $\mathrm{CHCl}_{3}$. The fact that the product was soluble indicates that no cross-linking took place and that the polymer has a hyperbranched structure.

70 Polymerization of (-)-2,4,7-tris(bromomethyl)-9neomenthylfluorene has been also conducted. However, the product was mostly insoluble in THF and $\mathrm{CHCl}_{3}$. The pentyl group at the 9-position of the fluorene ring seems to effectively prevent closs-linking in polymerization and also 75 interchain interaction to result in high solubitliy of the hyperbranched polymer.

The product was purified by reprecipitation in methanol (Mn 29800, Mw/Mn 8.37 (vs. polystyrene)). Further, lowermolecular-weight fractions were removed from the product by 80 fractionation using acetone. The acetone-insoluble part (58 $\mathrm{wt} \%$ ) had higher molecular weight (Mn 74300, Mw/Mn 4.77, $[\alpha]_{\mathrm{D}}{ }^{25}-64^{\mathrm{o}}\left(\mathrm{CHCl}_{3}, 1 \mathrm{~g} / \mathrm{dL}, 0.1-\mathrm{dm}\right.$ cell $\left.)\right)$. Hereafter, structure and properties of the acetone-insoluble polymer are discussed.

The polymers is considered to consist of dendritic or 85 branching (D), linear (L), and terminal (T) units. ${ }^{10,11}$ The ratio of these units was estimated from ${ }^{1} \mathrm{H}$ NMR spectrum of the polymer following the method of literature ${ }^{7 a}$ and was used for the calculation of degree of branching (DB) which is defined as $\mathrm{DB}=([\mathrm{D}]+[\mathrm{T}]) /([\mathrm{D}]+[\mathrm{L}]+[\mathrm{T}])^{10,11}(\mathrm{ESI}) . \quad \mathrm{D} / \mathrm{L} / \mathrm{T}$ 90 was $0.23 / 0.23 / 0.54$, and DB was 0.77 . The DB of the chiral hyperbranched polymer was higher than that of the achiral, parent polymer $^{7 \mathrm{a}}$ (DB 0.45 0.70). Bulkiness of neomenthyl group might reduce propagation giving linear units.

Chirality of the monomer and the polymer was examined 95 by circular dichroism (CD) spectra (Fig. 1). The monomer indicated a Cotton effect with a negative signal corresponding to UV absorptions in a THF solution in the range of 
wavelength shorter than $350 \mathrm{~nm}$, indicating that the $\pi$ electrons in fluorene unit of the monomer are in a chiral environment under the effect of the neomenthyl group (Fig. $1 \mathrm{~A})$. Kuhn's dissymmetry factor $(\mathrm{g}=\Delta \varepsilon / \varepsilon)$ was $-0.63 \times 10^{-4}$ 5 at $300 \mathrm{~nm}$. The polymer also showed an intense CD spectrum in a THF solution (Fig. 1B). The UV spectrum of the polymer indicated a strong band peaked around $375 \mathrm{~nm}$ that was not seen in the monomer spectrum. This band may be based on the fluorenevinylene conjugation system. That the polymer 10 indicated $\mathrm{CD}$ absorptions in the entire wavelength range where the polymer absorbs suggests that the entire conjugation system is under the chiral effect of the neomenthyl group. The $\mathrm{g}$ factor at $300 \mathrm{~nm}$ was $-0.99 \times 10^{-4}$.
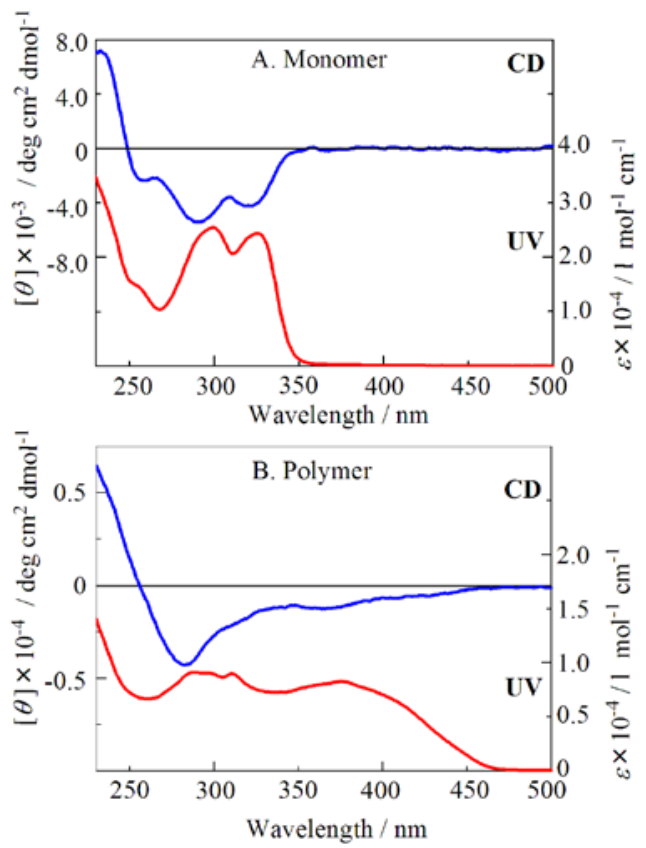

15

Fig. 1 CD and UV spectra of (-)-2,4,7-tris(bromomethyl)-9neomenthyl-9-pentylfluorene (monomer) (A) and the hyperbranched polymer (B). [in THF, room temperature, conc. $1.00 \times 10^{-3} \mathrm{M}$ ]

20

The polymer also indicated a CD spectrum in a spin-coated film form. The spectral shape was similar to that in solution with $\mathrm{g}$ factor at $300 \mathrm{~nm}$ of $-1.44 \times 10^{-4}$, suggesting that the chiral structure of the polymer does not largely change by film 25 fabrication.

Fig. 2 shows the fluorescence spectra of the polymer in solution and in film on irradiation at $378 \mathrm{~nm}$. Both in solution and in film, the polymer exhibited a broad emission band in the range of $400-700 \mathrm{~nm}$. The film emission was as intense as 30 the solution emission and was slightly red shifted.

CPL emission of the polymer was measured by irradiating the film at 375-nm pulsed laser light. ${ }^{8 \mathrm{a}}$ The CPL-fluorescent spectra are shown in Fig. 3A. A significant difference in intensity between right-handed (R-) and left-handed (L-) CPL 35 emission was confirmed. The photo luminescent dissymmetry factor ( $\mathrm{g}_{\mathrm{PL}}$ ) was calculated according to $\mathrm{g}_{\mathrm{PL}}=2(\mathrm{IL}-$ IR)/(IL+IR), where IL and IR are the intensities of L- and and $\mathrm{R}-\mathrm{CPL}$ emission, respectively, and its dependence on wavelength is shown in Fig. 3B. gPL value was highest (-0.45) 40 at $430 \mathrm{~nm}$ and was -0.16 at $490 \mathrm{~nm}$ (emission peak maximum). These $g_{P L}$ values are ca. $10^{3}$ times greater than the g values for $\mathrm{CD}$ absorption of the polymer and the monomer.

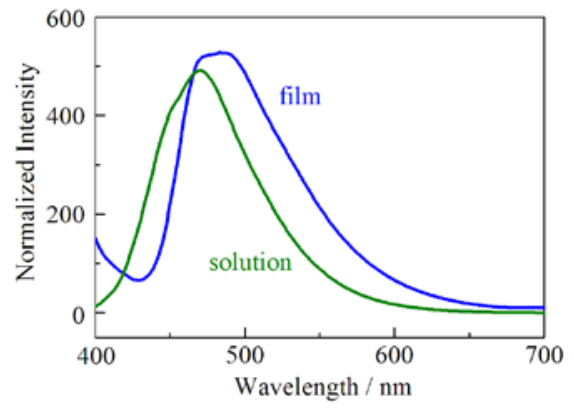

Fig. 2 Fluorescence spectra of hyperbranched polymers in THF solution and in film obtained by excitationat $378 \mathrm{~nm}$. Intensity was normalized to a constant absorbance at $378 \mathrm{~nm}$. [solution samples, conc. $1.00 \times 10^{-5} \mathrm{M}, 1-\mathrm{cm}$ cell]

50
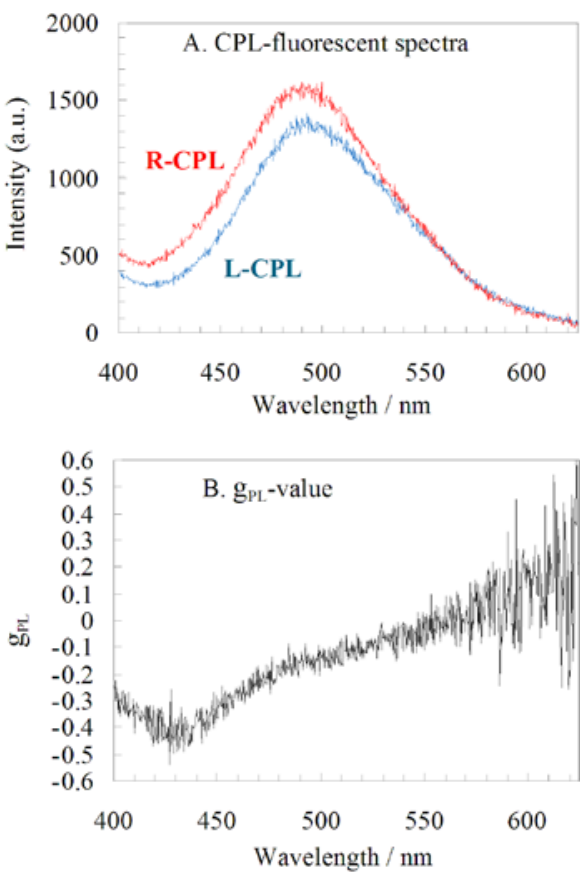

Fig. 3 CPL-fluorescent spectra (A) and $g_{P L}-v s$.-wavelength plot (B) of the hyperbranched polymer film. The spectra were obtained on 55 excitation at $375 \mathrm{~nm}$.

The g $_{P L}$ values observed here of the order of $10^{-1}$ are comparable to those reported for polymers with highlyordered intra- and intermolecular structures ${ }^{9}$ and those for 60 crystalline or liquid crystalline low-molecular-weight compound systems. ${ }^{8}$ This is noteworthy because the hyperbranched polymer studied in this work was not annealed to attain ordered structures. In addition, hyperbranched polymers generally do not have close chain packing. ${ }^{11}$

65 Lack of highly-ordered structures in the polymer was supported by the following examinations. Differential 
scanning calorimetric (DSC) analyses of the polymer indicated no clear exo- or endothermic transitions from room temperature to $195^{\circ} \mathrm{C}$ at which the polymer starts to decompose (ESI). In addition, polarized microscopic 5 observations of the film sample used for the CPL experiments did not show any textures suggesting ordered structures.

Furthermore, difference in light transmittance between Land R-CPL in the wavelength range of $400-700 \mathrm{~nm}$, where the polymer emits light and does not absorb light, was too small 10 to explain the $g_{P L}$ values; $g$ values for transmission were of the order of $10^{-2}$ (ESI). In addition, L-CPL was found to more readily transmit the film than $\mathrm{R}-\mathrm{CPL}$ while $\mathrm{R}-\mathrm{CPL}$ was more intense than L-CPL in emission. These results most conclusively indicate that the observed, effective CPL 15 emission is not due to ordering in the film.

In order to obtain information on the reason why the chiral hyperbranched polymer shows large $\mathrm{g}_{\mathrm{PL}}$ values, the CPL emission spectrum of 9-neomenthyl-9-pentylfluorene, as a model monomeric unit, was measured in a THF solution (ESI). 20 This unit has never been used as a part of repeating units in polymers to the best of our knowledge. In contrast to the hyperbranched polymer, this compound showed only moderate CPL emission with a g value of $10^{-4}$ order. This result clearly indicates that the observed intense CPL emission

25 from the hyperbranched polyemr is not due to this particular and unprecedented chiral moiety in the polymer structure. Based on this conclusion, we propose that a rather amorphous state in the solid state may enhance CPL emission for the hyperbranched polymer while ordered intra- and interchain 30 structures play an important role in CPL emission for linear polymers. $^{9}$

Furthermore, the hyperbranched polymer showed only weak CPL emission in a THF solution (ESI). This means that solid-state, amorphous polymer structure is important to 35 enhance CPL emission.

In addition, the acetone-soluble, lower-molecular-weight fraction (Mn 7300, Mw/Mn 3.71, $[\alpha]_{\mathrm{D}}{ }^{25}-67^{\circ}\left(\mathrm{CHCl}_{3}, 1 \mathrm{~g} / \mathrm{dL}\right.$, $0.1-\mathrm{dm}$ cell), DB 0.73) obtained from the original polymerization product indicated CPL emission with much 40 less efficiency compared with the acetone-insoluble, highermolecular-weight polymer discussed so far (ESI). This suggests that an extended hyperbranched structure enhances CPL emission. The extended hyperbranched structure may result in a more amorphous material.

45 In conclusion, we have synthesized a novel, chiral, hyperbranched poly(fluorenevinylene) derivative and found its effective CPL emission. This work has shown for the first time that effective CPL emission can be attained without the aid of molecular ordering and that an amorphous state may 50 even enahnce CPL emission ability.

We thank Prof. M. Fujiki (NAIST, Japan) for CPL emission measurements of 9-neomenthyl-9-pentylfluorene and Dr. H. Higashimura, Dr. K. Kobayashi, and Dr. H. Hayasaka (Sumitomo Chemical) for helpful advises. This study was 55 supported in part by the MEXT through Grants-in-Aid No. 21655037 and No. 22350047, and through the Global COE Program (Project No. B01: Catalysis as the Basis for Innovation in Materials Science) and in part by the Asahi
Glass Foundation.

60

\section{Notes and references}

1 (a) M. T. Bernius, M. Inbasekaran, J. O'Brien and W. S. Wu, Adv. Mater. 2000, 12, 1737; (b) E. Neher, Macromol. Rapid Commun. 2001, 22, 1366; (c) U. Scherf and E. J. W. List, Adv. Mater. 2002, 14, $65 \quad 477$

2 (a) J. H. Burroughes, D. D. C. Bradley, A. R. Brown, R. N. Marks, K. Mackay, R. H. Friend, P. L. Bruns and A. B. Holmes, Nature 1990, 347, 539; (b) P. W. M. Blom, Mater. Sci. Eng. 2000, 27, 53.

3 (a) A. C. Grimsdale, K. L. Chan, R. E. Martin, P. G. Jokisz and A. B. $70 \quad$ Holmes, Chem. Rev. 2009, 109, 897; (b) A. Kraft, A. C. Grimsdale and A. B. Holmes, Angew. Chem., Int. Ed. 1998, 37, 402.

4 (a) J. Teetsov and M. A. Fox, J. Mater. Chem. 1999, 9, 2117; (b) E. Zojer, A. Pogantsch, E. Hennebicq, D. Beljonne, J.-L.Bredas, P. S. de Freitas, U. Scherf and E. J. W. List, J. Chem. Phys. 2002, 117, 6794;

75 (c) E. J. W. List, R. Guentner, P. S. de Freitas and U. Scherf, Adv. Mater. 2002, 14, 374.

5 (a) N. G. Pschirer and U. H. F. Bunz, Macromolecules 2000, 33, 3961; (b) C. Schmitt, H. G. Nothofer, A. Falcou and U. Scherf, Macromol. Rapid Commun. 2001, 22, 624; (c) M. Kreyenschmidt, G.

80 Klärner, T. Fuhrer, J. Ashenhurst, S. Karg, W. D. Chen, V. Y. Lee, J. C. Scott and R. D. Miller, Macromolecules 1998, 31, 1099; (d) J. I. G. Lee, M. H. Daver and R. D. Miller, Synth. Met. 1999, 102, 1087; (e) C. Xia and R. C. Advincula, Macromolecules 2001, 34, 5854; (f) B. Liu, W. L.Yu, Y. H. Lai and W. Huang, Macromolecules 2000, 33, 8945.

6 (a) S. Setayesh, A. C. Grimsdale, T. Weil, V. Enkelmann, K. Müllen, F. Meghdadi, E. J. W. List, G. Leising, J. Am. Chem. Soc. 2001, 123, 946; (b) D. Marsitzky, R. Vestberg, P. Blainey, B. T. Tang, C. J. Hawker and K. R. Carter, J. Am. Chem. Soc. 2001, 123, 6965; (c) G. Klärner, R. D. Miller and C. J. Hawker, Polym. Prepr. 1998, 39, 1006; (d) A. J. Berresheim, M. Müller and K. Müllen, Chem. Rev. 1999, 99, 1747; (e) F. Morgenroth, E. Reuter and K. Müllen, Angew. Chem. 1997, 109, 647.

7 (a) L.-R. Tsai and Y. Chen, Macromolecules 2008, 41, 5098; (b) 95 L.-R. Tsai and Y. Chen, Macromolecules 2007, 40, 2984.

8 (a) R. K. Vijayaraghavan, S. Abraham, H. Akiyama, S. Furumi, N. Tamaoki and S. Das, Adv. Funct. Mater. 2008, 18, 2510; (b) Y. Geng, A. Trajkovska, S. W. Culligan, J. J. Ou, H. M. P. Chen, D. Katsis and S. H. Chen, J. Am. Chem. Soc. 2003, 125, 14032; (c) Y. Geng, A. Trajkovska, D. Katsis, J. J. Ou, S. W. Culligan and S. H. Chen, J. Am. Chem. Soc. 2002, 124, 8337; (d) K. E. S. Phillips, T. J. Katz, S. Jockusch, A. J. Lovinger and N. J. Turro, J. Am. Chem. Soc. 2001, 123, 11899; (e) F. Stomeo, C. Lincheneau, J. P. Leonard, J. E. O’Brien, R. D. Peacock, Colin P. McCoy and T. Gunnlaugsson, J. 105 Am. Chem. Soc. 2009, 131, 9636; (f) J. E. Field, G. Muller, J. P. Riehl and D. Venkataraman, J. Am. Chem. Soc. 2003, 125, 11808.

9 (a) M. Oda, H.-G. Nothofer, U. Scherf, V. Sunjic, D. Richter, W. Regenstein and D. Neher, Macromolecules 2002, 35, 6792; (b) D. Katsis, H. P. Chen, S. H. Chen, L. J. Rothberg and T. Tsutsui, Appl. Phys. Lett. 2000, 77, 2982; (c) J. N. Wilson, W. Steffen, T. G. McKenzie, G. Lieser, M. Oda, D. Neher, U. H. F. Bunz, J. Am. Chem. Soc. 2002, 124, 6830; (d) M. Oda, H.-G. Nothofer, G. Lieser,; U. Scherf, S. C. J. Meskers and D. Neher, Adv. Mater. 2000, 12, 362; (e) S. C. J. Meskers, E. Peeters, B. M. W. Langeveld-Voss and R. A. J. Janssen, Adv. Mater. 2000, 12, 589; (f) E. Peeters, M. P. T. Christiaans, R. A. J. Janssen, H. F. M. Schoo, H. P. J. M. Dekkers and E. W. Meijer, J. Am. Chem. Soc. 1997, 119, 9909; (g) A. Satrijo, S. C. J. Meskers and T. M. Swager, J. Am. Chem. Soc. 2006, 128, 9030; (h) Y. Nakano, Y. Liub and M. Fujiki, Polym. Chem. 2010, 1, 460.

10 C. J. Hawker and J. M. J. Frechet, J. Am. Chem. Soc. 1990, 112, 7638.

11 M. P. Stevens, In Polymer Chemistry, Oxford University Press, New York, 1999, pp. 353-354. 